\title{
PREVALENCE AND RISK FACTORS OF FUNGAL NASAL POLYPOSIS IN TERTIARY CARE HOSPITAL.
}

1. MBBS, DLO, FCPS

Professor ENT

Abbasi Shaheed Hospital, Karachi.

2. MBBS, DLO, MS

Consultant ENT

Abbasi Shaheed Hospital, Karachi.

3. MBBS, DLO, FCPS, Diploma in

Speech Pathology.

Assistant Professor ENT

Abbasi Shaheed Hospital, Karachi.

4. MBBS, DLO, MS

Associate Professor ENT

Abbasi Shaheed Hospital, Karachi.

5. MBBS

Demonstrator Pathology

Karachi Medical and Dental College, Karachi.

6. MPA (HRM), MASP, Speech

Therapist

Abbasi Shaheed Hospital, Karachi.

Correspondence Address:

Prof. Ayub Musani

Professor ENT

Abbasi Shaheed Hospital, Karachi.

ayubmusani@yahoo.com

Article received on:

06/04/2019

Accepted for publication:

15/09/2019

\section{INTRODUCTION}

Rhino-sinusitis is define as inflammation of mucosa of nose and paranasal sinus and affects up to $13 \%$ of population. ${ }^{1}$ It may be divided into acute ( $<$ four weeks), sub-acute (between four to twelve weeks) and chronic rhino-sinusitis (> twelve weeks). ${ }^{2}$ Chronic rhino-sinusitis is more common than acute form and its cause's negative impact in health. ${ }^{3}$ Fungal infection here suspected to be the causative agent of chronic rhino-sinusitis and a fungal etiology was found to underlie severe nasal polyps. ${ }^{4}$ Fungi spore abundantly present in environment and inhalation in unavoidable. ${ }^{5}$ When these spores inhale they may colonize in respiratory epithelium and paranasal sinus mucosa where they cause noninvasive and invasive type of disease depend upon the immunity, and age of the host. ${ }^{5,6,7}$

Fungal rhino-sinusitis categorized in to non- invasive and Invasive depend upon the mucosal invasion. Invasive fungal rhino-sinusitis further divided into acute invasive, chronic invasive and granulomatous type, while non-invasive fungus related eosinophilic rhino-sinusits and fungal ball. ${ }^{8}$ Chronic fungal rhinosinusitis further categorized into fungus related eosinophilic rhinosinusitis, granulomatous, fungal ball and chronic invasive. ${ }^{9}$ Different types of fungal species have been found in invasive fungal sinusitis particularly Aspergillus and Zygomyces. ${ }^{10}$ Multiple risk factors are responsible for fungal rhino-sinusitis like occupation, socio-economy, geographical factors, immune status of the patient CT scan nose and para-nasal sinuses play important role to assess the disease and extend of the disease. CT scan shows double density sign due to deposition of calcium salts such as calcium sulfate and calcium phosphate which helps in the diagnosis and extend of the disease. Fungal 
balls show more heterogeneous component on radiology and allergic fungal mucin show more radiodense. ${ }^{11}$

The incidence of fungal infection has dramatically increased in recent years. ${ }^{12}$ Prevalence of fungal infections in not precisely documented in Pakistan. In our study, try to determine the prevalence and risk factors of fungal sinusitis.

\section{MATERIAL AND METHODS}

This study was conducted in Otorhinolaryngology department of Abbasi Shaheed Hospital and Karachi Medical and Dental College. This hospital is a tertiary care and teaching hospital which cover the large population. This prospective study is conducted between two and half years, started from 17 October 2014 to April 2017. In this study those cases were included that came with clinical diagnosis of nasal polyps. Both sexes were included in this study. After informed consent, complete history was taken and noted in pre designed Performa. Complete physical and ENT examination was done. Eyes were also examined for any orbital involvement and if required taking expert opinion from Eye department. Necessary laboratory investigations were done. C-T scan were advised to see extend of the disease. After surgery specimen sent in formalin for histopathology and in normal saline for fungal Culture and sensitivity.

\section{Inclusion Criteria}

All patients who have nasal polyps on the clinical basis were included in this study

\section{Exclusion Criteria}

Any mass other than nasal polyp (Clinically diagnosed).

Not come on follow-up

\section{RESULTS}

Total number of patients selected for this study was 221. Histopathological evaluation revealed fungal polyposis was 90 patients (40.72\%) and remaining were simple allergic polyps 131 (59.27\%). Figure-1 shows prevalence of fungal rhino-sinusitis, the overall prevalence of fungal rhino-sinusitis was found in 90 patients (40.70\%).
Figure-2 show socio-economical status, mostly patients belong to poor socio-economical status i.e. $59(65.55 \%)$ followed by middle class 18 (20\%) patients. Table shows mean age, mean age was $30.16+/$ 12.33. Figure-3 shows gender differences, male were $55(61 \%)$ and female were $35(38.8 \%)$ with male female ratio was $1: 1.57$. Table-Il shows risk factors, highest number of patients were farmers 36 (40\%). Immunocompromised patients were $27(30 \%)$ and working with pets $28(31.1 \%)$ patients $36(40 \%)$ patients were farmers while history of allergy found in 35 patients (38.88\%).

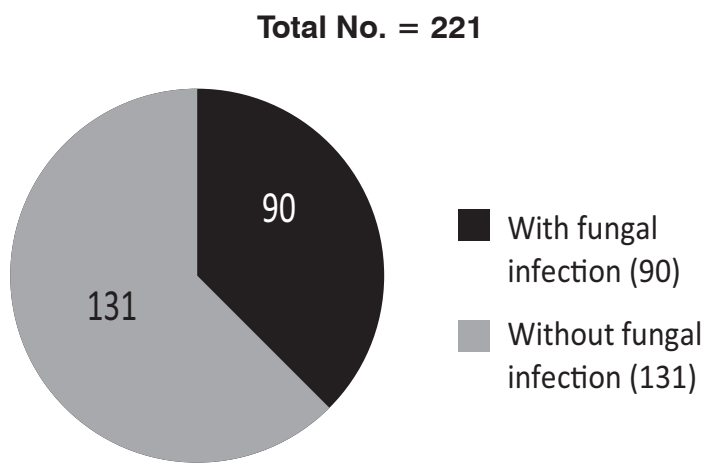

Figure-1. Prevalence of fungal rhino sinusitis.

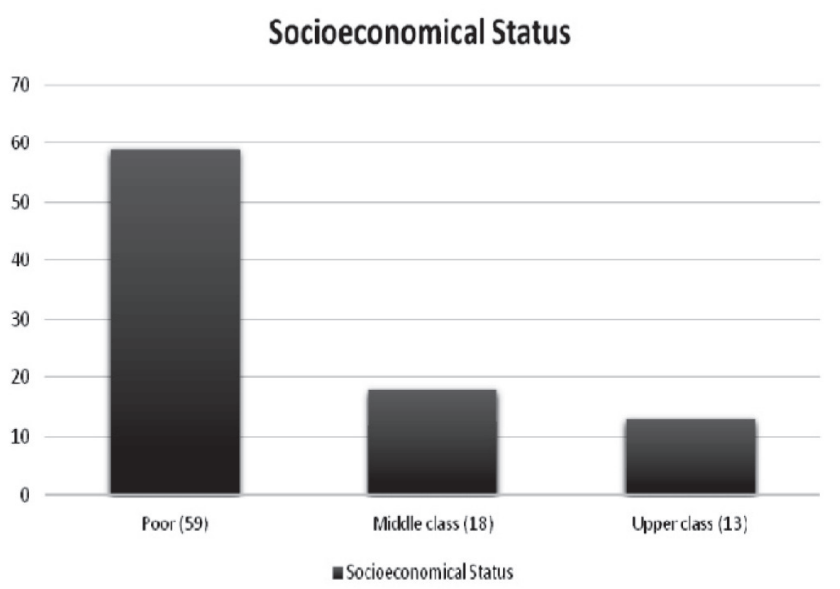

Figure-2. Socio-economical status.

\begin{tabular}{|c|c|}
\hline Mean & $\pm S D$ \\
\hline 30.16 & 12.33 \\
\hline
\end{tabular}




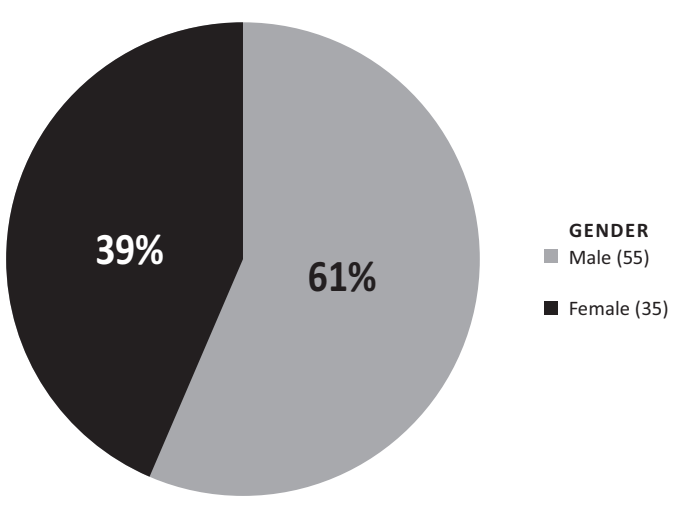

Figure-3. Gender.

\begin{tabular}{|l|c|}
\hline \multicolumn{1}{|c|}{ Risk Factor } & No. of Patients \\
\hline Farming & $36(40 \%)$ \\
\hline Working with pets & $28(31.1 \%)$ \\
\hline Immuno-compromise patient & $27(30 \%)$ \\
\hline History of allergy in family & $30(33.3 \%)$ \\
\hline Communicable disease & $30(33.3 \%)$ \\
\hline History of allergy in patient & $35(38.88 \%)$ \\
\hline \multicolumn{2}{|c|}{ Table-II. Risk factors. } \\
\hline
\end{tabular}

\section{DISCUSSION}

This was a prospective study conducted at Abbasi Shaheed Hospital Karachi. The prevalence of fungal nasal polyposis was found in 90 (40.70\%) cases as compared to the study conducted by Siddiqui et.al, who found fungal nasal polyposis in $69.75 \%$ cases out 324 patients presented with nasal polyposis. ${ }^{13}$ Another study also describe the relationship between nasal polyp and fungal sinusitis, 12 patients of nasal polyposis were selected in which 10 cases (83.33\%) were diagnosed fungal polyposis. ${ }^{14}$ Both study showed slight more prevalence of fungal infection as compared to above study. Most of the patients belong to poor socio-economical status about $65.5 \%$ followed by middle class families $20 \%$. According to the study of Jawad A, 83.3\% belong to low socio-economical Class. ${ }^{15}$ Study showed positive relationship between fungal sinusitis and poor socio-economical status. Fungal infection may occur at any age group, but clinical presentations depend upon the host immunity. ${ }^{7}$ In our study the mean age was $30.16+/ \ldots 12.33$ which is very close to the study of Haq M.I et.al ${ }^{16}$ $31.56+\ldots 6.18$ years. Zakir study showed mean age of disease was 20 years. ${ }^{17}$ In the above study male was $61.1 \%$ and female was $38.8 \%$. Male female ratio was 1.53. Regarding the gender distribution different studies showed different ratios. In Haq et.al study showed male female ratio was $1: 2^{16}$ which is closed to above study while Thalim k. et.al and Mian M.Y et.al showed male female ratio was 7:3 and 3:1 respectively. ${ }^{17,18}$

In risk factors, immune compromised patients were more prone to develop fungal infections in chronic sinusitis. In above study 27 (30\%) patients were immune compromised (e.g poorly controlled diabetes mellitus, malignancy or taking chemotherapy treatment). Tehmeena wani et. al study showed $22.22 \%$ patients were immuno compromised and mostly had history of poorly diabetic mellitus and hematological malignancy. ${ }^{19}$ Farmers have 3 times more chances to develop fungal nasal polyposis. ${ }^{19}$ In the above study 36 (40\%) patients were farmers. Tehmeena Wani study showed $29.63 \%$ patients were farmers ${ }^{19}$, which is closed to the above study. Chakarbati et.al found a greater risk of fungal rhino sinusitis among those who were farmers. ${ }^{20}$ Other risk factors included history of allergy found in 35 patients (38\%) and 30 (33.33\%) patients had positive history of allergy in family.

\section{CONCLUSION}

Our study reveals that prevalence of fungal rhinosinusitis is higher and multifactorial risk factors. Proper assessment of the disease should be done to prevent the disease, its recurrence and un-necessary complications. Higher incidence in farmers needs awareness and preventive measures.

\section{Copyright $(15$ Sep, 2019.}

\section{REFERENCES}

1. Pleis JR, Lucas JW, Ward BW. Summary health statistics for US. Adults: National Health Interview survey, 2008. Vital Health Stat 10 2009; (242):1-157.

2. Naghibzadeh B, Razmpa E, Alavi SH, Emami M, Shidfar M, Naghibzadeh GH, Morteza A. Prevalence of Fungal infection among Iranian patients with chronic sinusitis. Acta Otorhinolaryngol Ital. 2011 Feb; 31(1):35-38. 
3. Rosenfeld RM, Andes D, Bhattacharyya N, et al. Clinical practice guideline: Adult sinusitis. Otolaryngol Head Neck Surg. 2007; 137(Suppl 3):S1-S31.

4. Zaini KPF, Sabokbar A, Borghei H, Sara M. Fungi as causative agent of nasal polyps. Iranian J Pub Health, 2006, Vol. 35, No. 1, 53-57.

5. George R, Thompson III, Thomas F, Patterson MD. Fungal disease of the nose and paranasal sinuses. $J$ Allergy Clin Immunol 2012; 129:321-6.

6. Krishnan S, Manavathu EK, Chandrasekar PH. Aspergillus flavus: An emerging non-fumigatus Aspergillus species of significance. Mycoses. 2009; 52:206-2.

7. Suresh S, Arumugam D, Zacharaias G, Palaninathan $\mathrm{S}$, Vishwanath R, Venkatraman V. Prevalence and clinical profile of fungal rhino sinusitis. Allergy Rhinol (providence). 2016 summer; 7 (2): e 115-e120.

8. Chakrabarti A, Das A, Panda NK. Controversies surrounding the categorization of fungal sinusitis. Med Mycol. 2009; 47(Suppl 1):S299-S308.

9. Aribandi M, McCoy VA, Bazan C., 3rd Imaging features of invasive and noninvasive fungal sinusitis: $A$ review. Radiographics. 2007; 27:1283-96.

10. Fernandez J, Stanzani M, Tolomelli G, Pasquini E, Vianelli N, Baccarani M, Sciarrtta V. Sinonasal risk factors for the development of invasive fungal sinusitis in hematological patients: Are they important? Allergy Rhino (Providence). 2011 Jan-Mar; 2(1): 6-11.

11. Killeen DE, Sedaghat AR, Cunnane ME, Gray ST. Objective radiographic density measurements of sinus opacities are not strong indicators of noninvasive fungal diseases. Am J Rhinol Allergy 28:483-6, 2014
12. Joshi RR, Bhandary S, Khanal B, Sigh RK. Fungal Maxillary sinusitis: A prospective study in a tertiary care hospital of eastern Nepal Kathmandu University Medical Journal (2007), Vol. 5, No. 2. Issue 18, 195199.

13. Siddiqui $A H$, Sheikh AA, Khan TZ, Marfani MS, Ali A. Sinonasal polyposis and fungus: A growing relationship. Intern Jour of Endorsing Health Sci Research 2014; 2(1): 58-61.

14. Iqbal K, Saqlain G, Jalisi M. Nasal polyposis and fungal sinusitis. Pak J Otolaryngol. 1993; 9: 173-6.

15. Jawad A, Nisar YB. Frequency of fungal infection in the nasal polyposis patients undergoing polypectomy in a tertiary care unit. Rawal Medical Journal. 2015 Oct 1;40(4):428-32.

16. Haq Ml, Farooq M, Qadri SH. Prevalence of Allergic Fungal Sinusitis among patients with nasal polyps. JSZMC 2014; 5(4): 690-2.

17. Zakirullah, Nawaz G, Sattar GF. Presentation and diagnosis of Allergic fungal sinusitis. J Ayub Med Coll Abbottabad 2010, 22:53-57.

18. Mian MY, Kamal SA, Senthilkumaran G, Abdullah A, Pirani M. Allergic Fungal Rhnosinusitis: Current Status. Pak J Otolaryngol 2002; 18:36-40.

19. Midhat Amin MD, Kakru DK, Wani T, Qazi SM. FUNGAL RHINO SINUSITIS: PERIOD PREVALENCE AND RISK FACTORS-A PROSPECTIVE STUDY. JK-Practitioner. 2012 Jan;17(1-3):33-8.

20. Chakararti A, Sharma SC, Chander J. Epidemiology and pathogenesis of paranasal sinus mycosis. Head and neck Surg 1992; 107: 745-50.

\begin{tabular}{|c|c|c|c|}
\hline \multicolumn{4}{|c|}{ AUTHORSHIP AND CONTRIBUTION DECLARATION } \\
\hline Sr. \# & Author(s) Full Name & Contribution to the paper & Author(s) Signature \\
\hline 1 & Ayub Musani & Case collection / Research. & \\
\hline 2 & Qaisar Sajjad & Case collection / Research. & \\
\hline 3 & Faheem Ahmed Khan & $\begin{array}{l}\text { Case collection / Research / } \\
\text { Data collection. }\end{array}$ & \\
\hline 4 & Itrat Jawaid & $\begin{array}{l}\text { Case collection / } \\
\text { rephrasing. }\end{array}$ & \\
\hline 5 & & $\begin{array}{l}\text { Literature search / data } \\
\text { collection / drafting. }\end{array}$ & \\
\hline 6 & Aqeel-ur-Rehman Hameed & $\begin{array}{l}\text { Literature search and } \\
\text { Drafting. }\end{array}$ & \\
\hline
\end{tabular}

